\title{
Malnutrition in idiopathic pulmonary fibrosis: the great forgotten comorbidity!
}

To the Editor:

The publication by ToRRISI et al. [1] in the European Respiratory Journal evaluated the ability of comorbidities to improve the prediction of survival of idiopathic pulmonary fibrosis (IPF) patients. These variables are in addition to those in the best validated Gender-Age-Physiology (GAP) multivariable prediction model for mortality in IPF. The authors have added to the four parameters (age, sex, forced vital capacity per cent predicted and diffusing capacity of the lung for carbon monoxide per cent predicted) of the GAP model [2] comorbidities such as gastro-oesophageal reflux, pulmonary hypertension, lung cancer, valvular heart disease and atrial arrhythmias, which were found to have a significant impact on survival. They showed that the inclusion of comorbidities in TORVAN models significantly improved the prediction of the risk of death.

However, we were surprised that there was no mention of nutritional status despite growing evidence that IPF patients frequently suffer from malnutrition [3]. We now have evidence that malnutrition is also a prognostic factor (S. Jouneau and co-workers, unpublished results; see also $[4,5]$ ) and is suspected of involvement in several chronic diseases. For example, the body mass index (BMI) [6] or body fat-free mass [7] can be strong, independent predictors in chronic obstructive pulmonary disease (COPD) patients. It is conceivable that the negative effect of malnutrition on survival might be reversed by pulmonary rehabilitation in malnourished patients as demonstrated in COPD [8], in contrast to some of the significant variables (pulmonary hypertension, atrial arrhythmias or lung cancer) identified by ToRRISI et al. [1].

We, therefore, suggest that BMI or another nutrition variable should be included in the present study, if they are available, and in future work on predictive models for IPF patients.

Stéphane Jouneau $\oplus^{1,2}$, Mathieu Lederlin ${ }^{3}$, Laurent Vernhet ${ }^{2}$ and Ronan Thibault ${ }^{4}$

${ }^{1}$ Dept of Respiratory Medicine, Competences Centre for Rare Pulmonary Diseases, Pontchaillou Hospital, Rennes 1 University, Rennes, France. ${ }^{2}$ IRSET UMR1085, Rennes 1 University, Rennes, France. ${ }^{3}$ Dept of Radiology, CHU Rennes, LTSI, INSERM U1099, Univ Rennes, Rennes, France. ${ }^{4}$ INSERM, INRA, Univ Rennes, Nutrition Metabolisms and Cancer, NuMeCan, Nutrition unit, CHU Rennes, Rennes, France.

Correspondence: Stéphane Jouneau, Dept of Respiratory Medicine, Competences Centre for Rare Pulmonary Diseases, Pontchaillou Hospital, Rennes 1 University, 2 rue Henri Le Guilloux, 35033 Rennes Cedex 9, France.

E-mail: stephane.jouneau@chu-rennes.fr

Received: Feb 272019 | Accepted: March 012019

Conflict of interest: S. Jouneau reports current work on malnutrition and IPF funded by Boehringer Ingelheim and Roche/Genentech, during the conduct of the study; grants for research, personal fees and non-financial support for congress attendance, registration, travel and accommodation, personal fees for advisory board work and consultancy from Actelion, AIRB, AstraZeneca, BMS, Boehringer, Chiesi, Gilead, GSK, LVL, Mundipharma, Novartis, Pfizer, Roche and Savara-Serendex, outside the submitted work. M. Lederlin reports current work on malnutrition and IPF funded by Boehringer Ingelheim and Roche/Genentech, during the conduct of the study; personal fees from Boehringer Ingelheim, outside the submitted work. L. Vernhet reports current work on malnutrition and IPF funded by Boehringer Ingelheim and Roche/Genentech, during the conduct of the study. R. Thibault reports current work on malnutrition and IPF funded by Boehringer Ingelheim and Roche/Genentech, during the conduct of the study; and received royalties from Knoë, Le Kremlin Bicêtre, France for designing the Simplified Evaluation of Food Intake (SEFI) tool.

@ERSpublications

$\mathrm{BMI} /$ nutritional assessment should be part of the evaluation of IPF patients, since it has an impact on prognosis http://ow.ly/BBe930ocgx5

Cite this article as: Jouneau S, Lederlin M, Vernhet L, et al. Malnutrition in idiopathic pulmonary fibrosis: the great forgotten comorbidity! Eur Respir J 2019; 53: 1900418 [https://doi.org/10.1183/ 13993003.00418-2019]. 


\section{References}

1 Torrisi SE, Ley B, Kreuter M, et al. The added value of comorbidities in predicting survival in idiopathic pulmonary fibrosis: a multicentre observational study. Eur Respir J 2019; 53: 1801587.

2 Ley B, Ryerson CJ, Vittinghoff E, et al. A multidimensional index and staging system for idiopathic pulmonary fibrosis. Ann Intern Med 2012; 156: 684-691.

3 Jouneau S, Kerjouan M, Rousseau C, et al. What are the best indicators to assess malnutrition in idiopathic pulmonary fibrosis patients? A cross-sectional study in a referral centre. Nutrition 2018; 62: 115-121.

4 Nakatsuka $\mathrm{Y}$, Handa T, Kokosi M, et al. The clinical significance of body weight loss in idiopathic pulmonary fibrosis patients. Respiration 2018; 96: 338-347.

5 Nishiyama $\mathrm{O}$, Yamazaki R, Sano $\mathrm{H}$, et al. Fat-free mass index predicts survival in patients with idiopathic pulmonary fibrosis. Respirology 2017; 22: 480-485.

6 Celli BR, Cote CG, Marin JM, et al. The body-mass index, airflow obstruction, dyspnea, and exercise capacity index in chronic obstructive pulmonary disease. N Engl J Med 2004; 350: 1005-1012.

7 Schols AM, Broekhuizen R, Weling-Scheepers CA, et al. Body composition and mortality in chronic obstructive pulmonary disease. Am J Clin Nutr 2005; 82: 53-59.

8 Pison CM, Cano NJ, Cherion C, et al. Multimodal nutritional rehabilitation improves clinical outcomes of malnourished patients with chronic respiratory failure: a randomised controlled trial. Thorax 2011; 66: 953-960.

Copyright @ERS 2019

From the authors:

We appreciate the thoughtful comments of S. Jouneau and co-workers in their correspondence addressing the importance of nutritional status in idiopathic pulmonary fibrosis (IPF). We agree with the authors that nutritional status is of great interest in chronic diseases such as IPF [1].

The two most accepted methods to assess nutritional status are body mass index (BMI) and fat-free mass (FFM) [2-5]. Although BMI is the most widely used and simplest method, several factors such as ethnicity, gender and social status may influence it [6]. Moreover, it remains unestablished what cut-off value is the most appropriate to identify malnutrition [7]. Fat-free mass, a more sophisticated assessment technique using bioelectrical impedance, is not routinely performed in IPF patients. Thus, evidence for FFM is very limited in patients with IPF [8].

We agree that the central question of "what are the best indicators to assess malnutrition in IPF?" has to be addressed [1]. It was not possible to assess most indicators of malnutrition in the TORVAN study (e.g. FFM, weight loss, low energy intake, mid-arm circumference, triceps skinfold, etc.) as they were not routinely collected in the cohort [9]. In addition, only variables previously proven to be associated with survival were considered for our analytical model. While nutritional status is known to influence prognosis in some pulmonary diseases, such as chronic obstructive pulmonary disease and tuberculosis [3, 10], its impact on IPF remains uncertain. Furthermore, it should be considered that malnutrition in IPF is rather a consequence of the disease and not a comorbid condition per se. However, given the high prevalence of malnutrition in IPF patients, this "forgotten factor" is of great interest and we agree that its impact on mortality should be further evaluated.

@ERSpublications

The role of malnutrition in IPF remains uncertain and should be considered a consequence of the disease and not a comorbid condition. However, given the high prevalence of malnutrition in IPF its impact on mortality should be further evaluated. http://ow.ly/5CKe30okjma

Cite this article as: Torrisi SE, Ley B, Kreuter M, et al. Malnutrition in idiopathic pulmonary fibrosis: the great forgotten comorbidity! Eur Respir J 2019; 53: 1900615 [https://doi.org/10.1183/13993003.006152019].

Sebastiano Emanuele Torrisi ${ }^{1,2}$, Brett Ley $^{3}$, Michael Kreuter $^{2}$, Marlies Wijsenbeek ${ }^{4}$, Eric Vittinghoff ${ }^{5}$, Harold R. Collard ${ }^{3}$ and Carlo Vancheri ${ }^{1}$

${ }^{1}$ Regional Referral Centre for Rare Lung Diseases, University Hospital "Policlinico", Dept of Clinical and Experimental Medicine, University of Catania, Catania, Italy. ${ }^{2}$ Center for Interstitial and Rare Lung Diseases, Pneumology and Respiratory Critical Care Medicine, Thoraxklinik, University of Heidelberg, Heidelberg, Germany. ${ }^{3}$ Dept of Medicine, University of California, San Francisco, CA, USA. ${ }^{4}$ Dept of Respiratory Medicine, Erasmus University Medical Centre, Rotterdam, The Netherlands. ${ }^{5}$ Dept of Epidemiology and Biostatistics, University of California, San Francisco, CA, USA.

Correspondence: Carlo Vancheri, Regional Referral Centre for Rare Lung Diseases, A.O.U. Policlinico-Vittorio Emanuele, Dept of Clinical and Experimental Medicine, University of Catania, Via Santa Sofia 78, Catania, Italy. E-mail: vancheri@unict.it 
Received: March 272019 | Accepted: March 272019

Conflict of interest: S.E. Torrisi has nothing to disclose. B. Ley has nothing to disclose. M. Kreuter reports grants from Galapagos, grants and personal fees from Boehringer Ingelheim and from Hoffman la Roche, outside the submitted work. M. Wijsenbeek reports grants and other from Hoffman la Roche, grants and other from Boehringer Ingelheim, other from Galapagos, outside the submitted work; all grants and fees were paid to her institution. E. Vittinghoff has nothing to disclose. H.R. Collard reports personal fees from Bayer, Boehringer Ingelheim, Bristol-Myers Squibb, Global Blood Therapeutics, Genoa, ImmuneWorks, Navitor, Parexel, PharmAkea, Prometic, Toray, Unity, Patara, Veracyte, Roche/Genentech, aTyr, Advance Medical, Aeolus and MedImmune, grants from the Pulmonary Fibrosis Foundation, and grants and personal fees from Three Lakes Partners, all outside the submitted work. C. Vancheri has nothing to disclose.

\section{References}

1 Jouneau S, Kerjouan M, Rousseau C, et al. What are the best indicators to assess malnutrition in idiopathic pulmonary fibrosis patients? A cross-sectional study in a referral centre. Nutrition 2018; 62: 115-121.

2 Chailleux E, Laaban JP, Veale D. Prognostic value of nutritional depletion in patients with COPD treated by long-term oxygen therapy: data from the ANTADIR observatory. Chest 2003; 123: 1460-1466.

3 Landbo C, Prescott E, Lange $\mathrm{P}$, et al. Prognostic value of nutritional status in chronic obstructive pulmonary disease. Am J Respir Crit Care Med 1999; 160: 1856-1861.

4 Schols AM, Broekhuizen R, Weling-Scheepers CA, et al. Body composition and mortality in chronic obstructive pulmonary disease. Am J Clin Nutr 2005; 82: 53-59.

5 Vestbo J, Prescott E, Almdal T, et al. Body mass, fat-free body mass, and prognosis in patients with chronic obstructive pulmonary disease from a random population sample: findings from the Copenhagen City Heart Study. Am J Respir Crit Care Med 2006; 173: 79-83.

6 Wang Y, Beydoun MA. The obesity epidemic in the United States - gender, age, socioeconomic, racial/ethnic, and geographic characteristics: a systematic review and meta-regression analysis. Epidemiol Rev 2007; 29: 6-28.

$7 \quad$ Evans WJ, Morley JE, Argiles J, et al. Cachexia: a new definition. Clin Nutr 2008; 27: 793-799.

8 Nishiyama O, Yamazaki R, Sano $\mathrm{H}$, et al. Fat-free mass index predicts survival in patients with idiopathic pulmonary fibrosis. Respirology 2017; 22: 480-485.

9 Torrisi SE, Ley B, Kreuter $\mathrm{M}$, et al. The added value of comorbidities in predicting survival in idiopathic pulmonary fibrosis: a multicenter observational study. Eur Respir J 2019; 53: 1801587.

10 Miyata S, Tanaka M, Ihaku D. The prognostic significance of nutritional status using malnutrition universal screening tool in patients with pulmonary tuberculosis. Nutr J 2013; 12: 42. 